Review

\title{
New Researches Examines the Wing Shapes to Reduce Vortex and Wake
}

\author{
${ }^{1}$ Nicolae Petrescu, ${ }^{2}$ Raffaella Aversa, ${ }^{2}$ Antonio Apicella and ${ }^{3}$ Florian Ion Tiberiu Petrescu \\ ${ }^{1}$ Bucharest University, Bucharest, (CE), Romania \\ ${ }^{2}$ Department of Architecture and Industrial Design, Advanced Material Lab, \\ Second University of Naples, 81031 Aversa (CE), Italy \\ ${ }^{3}$ ARoTMM-IFToMM, Bucharest Polytechnic University, Bucharest, (CE), Romania
}

\author{
Article history \\ Received: $14-1-2018$ \\ Revised: $31-5-2018$ \\ Accepted: 12-6-2018 \\ Corresponding Author: \\ Florian Ion Tiberiu Petrescu \\ ARoTMM-IFToMM, \\ Bucharest Polytechnic \\ University, Bucharest, (CE), \\ Romania \\ E-mail: scipub02@gmail.com
}

Abstract: It is common to see clouds in the form of the sky, known as contrails, which are behind the engines of a reaction plan. What is not always visible is a wind whirl that comes out of the top of each wing - like two small horizontal tornadoes - leaving behind a turbulent awakening behind the vehicle. Awakening is a destabilizing flight hazard, especially for smaller aircraft that have the same flight path. Recent research at the University of Illinois has shown that although most of the wings used today create these turbulent vortices, wing geometry can be designed to reduce or eliminate almost the entire comma. In the study, the characteristics of vortex and awakening were calculated for three classical wings: wings and elliptical wings developed in the classical R.T. Jones and Ludwig Prandt. "The configuration of the elliptical wings has been used as the gold standard of aerodynamic efficiency for the best part of a century. We teach our students that they have optimal load characteristics and that they are often used when looking at wings efficiency, for example by minimizing traction, said Phillip Ansell, assistant professor at the Department of Aerospace Engineering at U of I. In a previous experimental study on optimizing wing configurations, Ansell has learned that you can achieve the efficiency of the wing system with a non-elliptical wing profile. Previous academic studies have shown that, in theory, there are other models that actually offer less resistance to a flat wing for a fixed amount of elevator generation. But what is missing is a real apple experiment - something else to prove it. In this new research, Ansell and his graduate student, Prateek Ranjan, used the real data from the previous study to analyze the configurations of the three wings. "We followed this because we saw a certain curiosity in our measurements in the previous experiment." In this new study, we simulated the flow of these three wings and we saw significant differences in how the vortexing and awakening of three Wings Wings Jones and Prandtl did not have peaks like elliptical wings, they had a more gradual deformation of the entire ditch than the immediate consistency of change. Now we know we can delay the formation of structures, the vortex awakens and increases our wishes for distance to pass 12 times, making it weaker and less dangerous for the plane to pass through it. "We look at how wing wings and information can be used to understand how the wind swirl process takes place. This study allows us to be aware of how the wings configuration affects wind formation and wakes up studying the extremes of the wind immediate and delayed, Ansell said. Interestingly, I found that one of the worst offenders creating vortexes is really the distribution."

Keywords: Wings Shapes, Elliptical Wings, Reduced Vortex, Reduced Wake 


\section{Introduction}

It is common to see clouds in the form of the sky, known as contrails, which are behind the engines of a reaction plan (Fig. 1). What is not always visible is a wind whirl that comes out of the top of each wing - like two small horizontal tornadoes - leaving behind a turbulent awakening behind the vehicle. Awakening is a destabilizing flight hazard, especially for smaller aircraft that have the same flight path.

Recent research at the University of Illinois has shown that although most of the wings used today create these turbulent vortices, wing geometry can be designed to reduce or eliminate almost the entire comma. In the study, the characteristics of vortex and awakening were calculated for three classical wings: wings and elliptical wings developed in the classical R.T. Jones and Ludwig Prandt.

"The configuration of the elliptical wings has been used as the gold standard of aerodynamic efficiency for the best part of a century.

We teach our students that they have optimal load characteristics and that they are often used when looking at wings efficiency, for example by minimizing traction, said Phillip Ansell, assistant professor at the Department of Aerospace Engineering at U of I.

In a previous experimental study on optimizing wing configurations, Ansell has learned that you can achieve the efficiency of the wing system with a non-elliptical wing profile.

Previous academic studies have shown that, in theory, there are other models that actually offer less resistance to a flat wing for a fixed amount of elevator generation. But what is missing is a real apple experiment - something else to prove it.
In this new research, Ansell and his graduate student, Prateek Ranjan, used the real data from the previous study to analyze the configurations of the three wings.

"We followed this because we saw a certain curiosity in our measurements in the previous experiment."

"In this new study, we simulated the flow of these three wings and we saw significant differences in how the vortexing and awakening of three Wings Wings Jones and Prandtl did not have peaks like elliptical wings, they had a more gradual deformation of the entire ditch than the immediate consistency of change."

Now we know we can delay the formation of structures, the vortex awakens and increases our wishes for distance to pass 12 times, making it weaker and less dangerous for the plane to pass through it. "

Ansell said that this information could be used to regulate flight mode between aircraft or to develop a new ideal configuration for loading the take-off and landing lift and to further reduce the distance between the aircraft in the same way as the bodies.

"The tip of the wing tends to escape when it forms in the atmosphere. So the time needed to dissipate the vortex must be removed, the next air that goes in the same direction it can create for the aircraft behind them, because it can be unpredictable to cause wings to Jones or Prandtl, would lead to much less turbulent air behind a plane, Ansell said.

You'd think Ansell's conclusion is to use only the Jones or Prandtl wings, but it's not.

"One of the things that first attracted me to aerodynamics is that the correct answer always depends on your constraints.

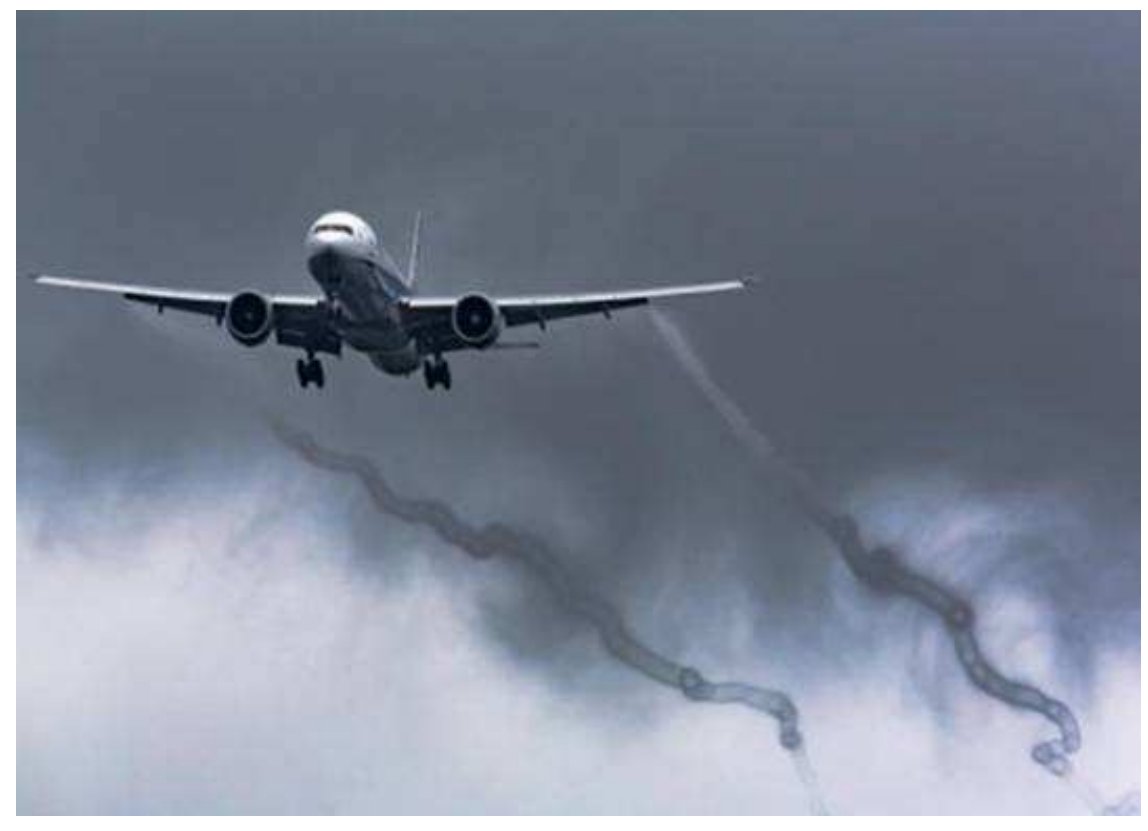

Fig. 1: This is a photo showing wake turbulence 
If you are building a tiny unmanned vehicle that will fly at a low speed, you will get a different solution for design needs than if you build an aircraft that will drive people at high altitudes and high speeds So from a technical point of view, you could claim that the three types of wings are the best solution. The question is: what are your driving constraints such as wings and weight, behind the choice of a?

Ansell added that this is a basic study and does not intend to advise a particular airplane designer or company.

"We look at how wing wings and information can be used to understand how the wind swirl process takes place. This study allows us to be aware of how the wings configuration affects wind formation and wakes up studying the extremes of the wind immediate and delayed," Ansell said.

"Interestingly, I found that one of the worst offenders creating vortexes is really the distribution" (Ranjan and Ansell, 2018).

\section{Methods and Materials}

With 22 successful flight tests over six months, a new type of wing, called the Adaptive Compliant Trailing Edge (ACTE), could equip the next generation of passenger airplanes, delivering silent and significant fuel savings (Fig. 2).

Created by NASA, the new wing model replaces rigid flaps with a mobile alternative made of composite material. Lighter than conventional flight surfaces, the new wings reduce the perceived noise during the flight and promise millions of dollars worth of fuel savings annually.

Depending on load, altitude and maneuver, the shape of the wings can be dynamically adjusted to achieve a curvature of between $-2^{\circ}$ and $30^{\circ}$, generating the optimum load with minimal turbulence and drag.

"The completion of this flight test campaign is a big step forward for the Environmentally Responsible Aviation (ERA) project." According to Fay Collier, the ERA project manager, this was the first of eight largescale demonstrations of targeted technologies to reduce the impact of aviation on the environment. The results obtained with the ACTE prototype are to be integrated with other future design studies conducted by NASA through the Langley Research Center (Harrington and Williams, 2015).

Some advanced concepts will be presented in Figs. 3-12.

An aviation renaissance, one focused on energy efficiency and economic impact, is on the horizon and it's changing how engineers look at aircraft power and design.

Although the aircraft industry continues to adopt innovative technologies, which are making current aircraft more energy efficient, there's new interest in exploring alternative propulsion systems and energy sources.
This new interest presents an opportunity to develop cutting-edge technologies that will dramatically reduce fuel usage while opening up potential new markets and business opportunities for American companies and carriers.

"I feel we are at a tipping point in commercial aviation," says Jim Heidmann, manager of NASA's Advanced Air Transport Technology Project (AATT). "We are exploring and developing game-changing technologies and concepts for aircraft and propulsion systems that can dramatically improve efficiency and reduce environmental impact and accelerate the introduction of new aircraft."

To provide better efficiency with less noise and fewer emissions, NASA is working with the aviation industry and academia to develop unique vehicle concepts that will use different fuselage shapes; longer, skinnier and more blended wings; innovative materials and components; and highly-integrated propulsion (engine) systems.

NASA aims to accelerate the final testing and validation of these advanced concepts and technologies through its New Aviation Horizons initiative.

This initiative outlines the development of a series of experimental planes (X-planes), which will achieve the agency's aircraft-level metrics for fuel consumption, emissions and noise.

The work has already begun under New Aviation Horizons as NASA is preparing to build and fly the first such X-plane - a low-boom supersonic flight demonstrator.

A turboelectric aircraft configuration is among several candidates for future subsonic transport X-planes that will prove the benefits of these advanced technologies in piloted flight within the next decade (Fig. 3-5).

Aeronautical innovations are part of a governmentindustry partnership to collect data that could make the supersonic flight over land possible, dramatically reducing travel time in the United States or anywhere in the world.

NASA's Low-boom Flight Demonstration mission has two goals: (1) design and build a piloted, large-scale supersonic X-plane with technology that reduces the loudness of a sonic boom to that of a gentle thump; and (2) fly the X-plane over select U.S. communities to gather data on human responses to the low-boom flights and deliver that dataset to U.S. and international regulators.

Using these data, new sound-based rules regarding supersonic flight over land could be developed, which would open the doors to new commercial cargo and passenger markets to provide faster-than-sound air travel (Fig. 6).

The subscale $\mathrm{X}-56 \mathrm{~A}$ is scheduled for a series of research flights in November to prove enabling technology for designing aircraft with highly flexible, lightweight wings. The use of less structurally-rigid wings could be critical to future long-range, fuelefficient airliners. 


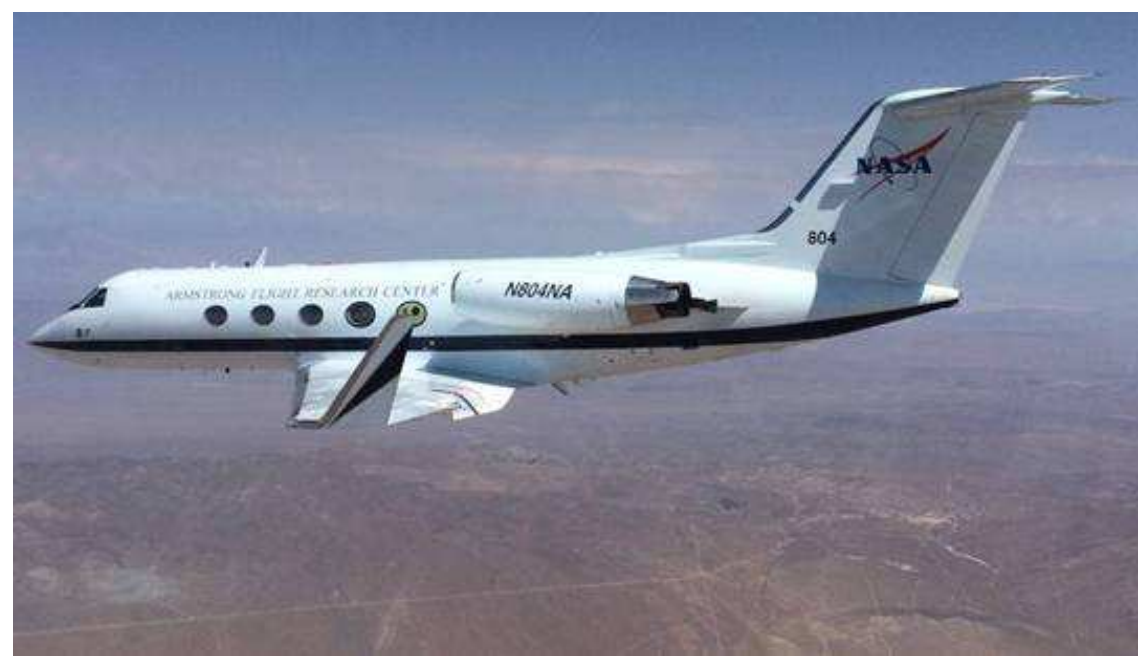

Fig. 2: Developed by NASA engineers - a winged prototype plane that changes shape in flight

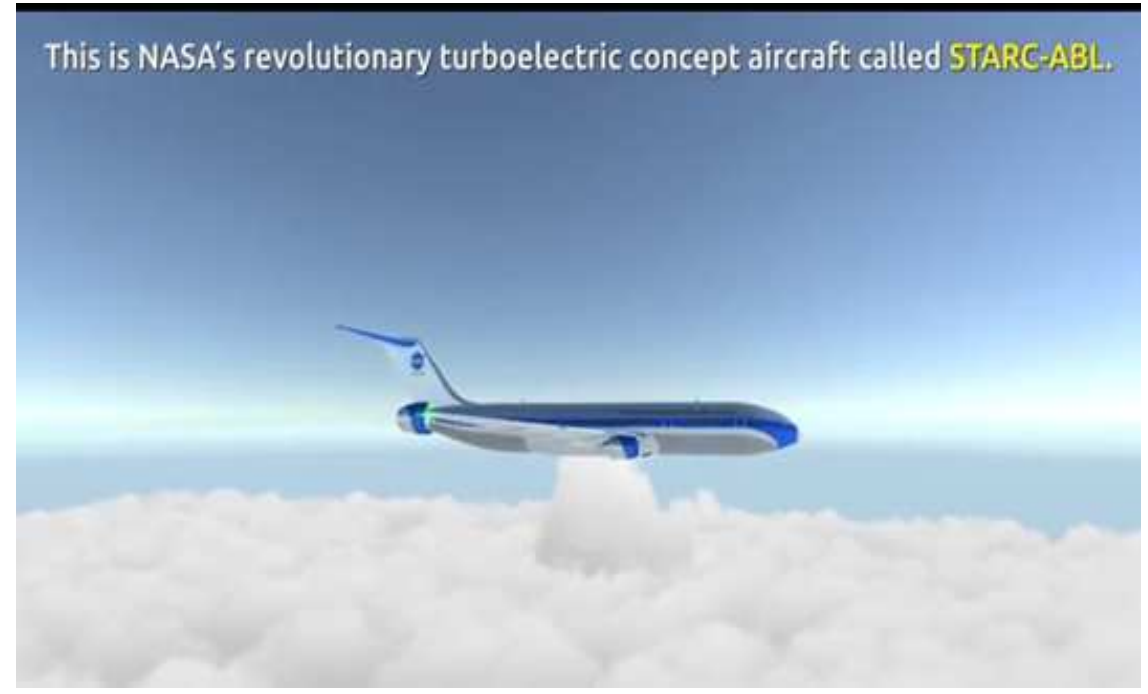

Fig. 3: A NASA revolutionary turboelectric concept

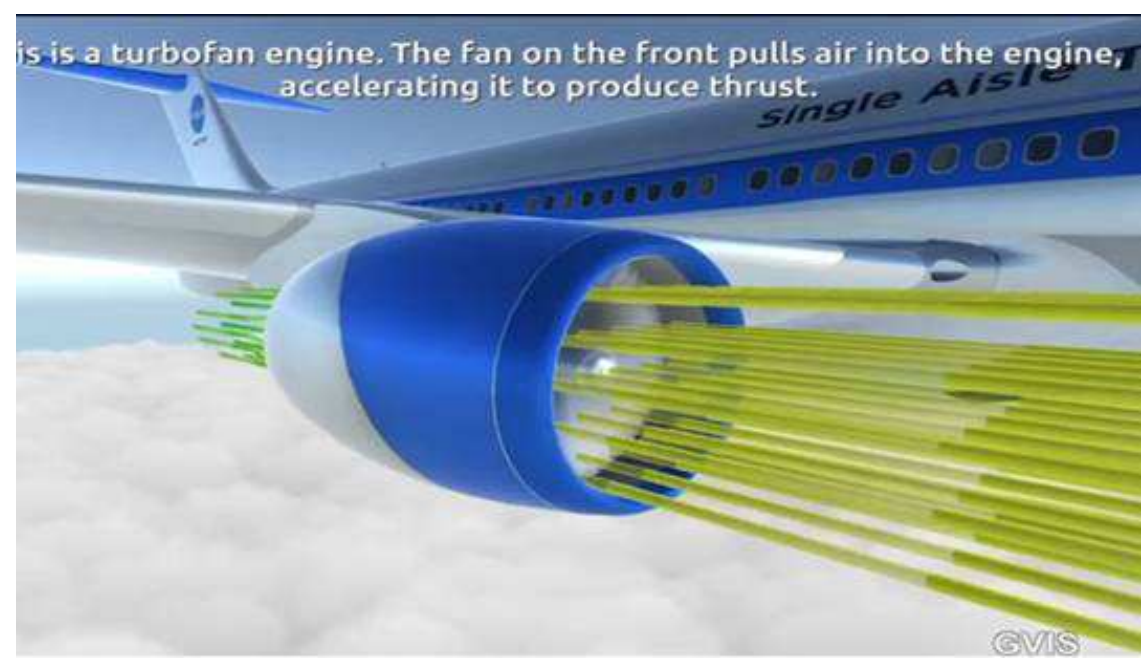

Fig. 4: A turbofan engine 


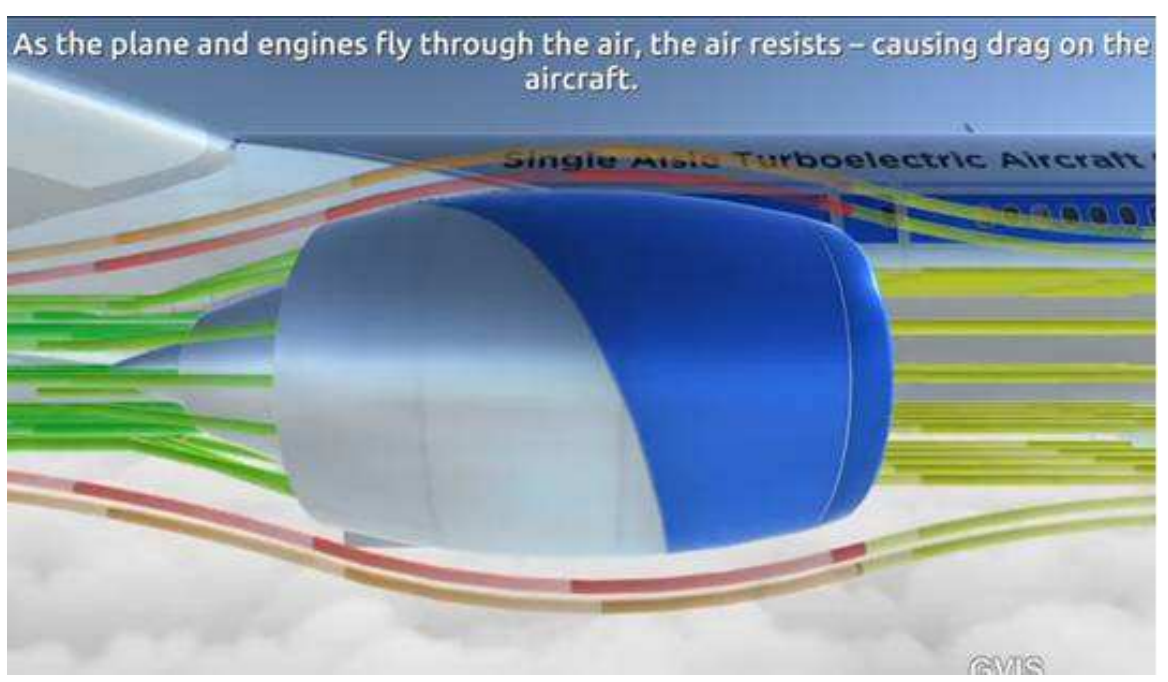

Fig. 5: A turbofan engine

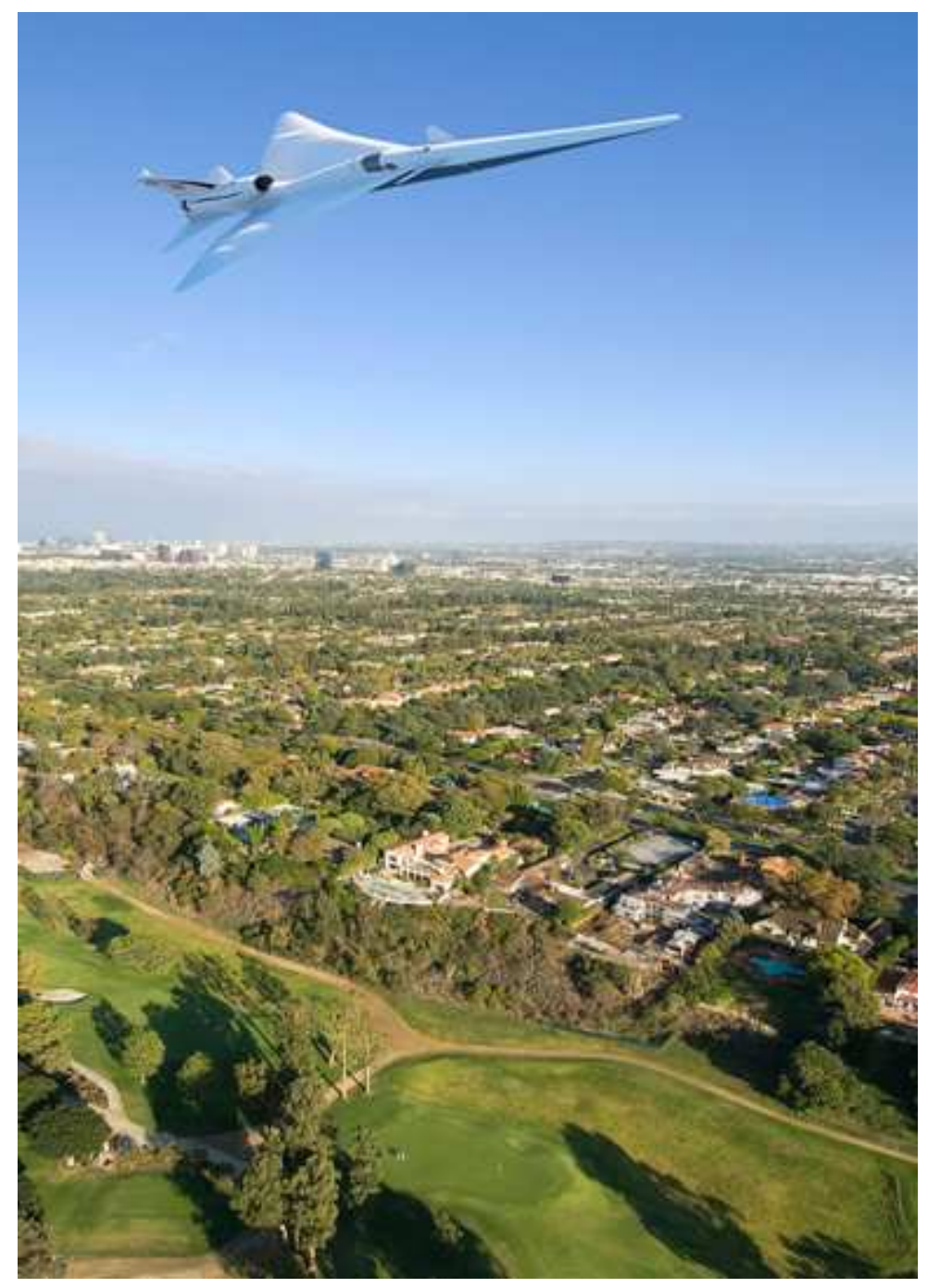

Fig. 6: Low-boom flight demonstration 


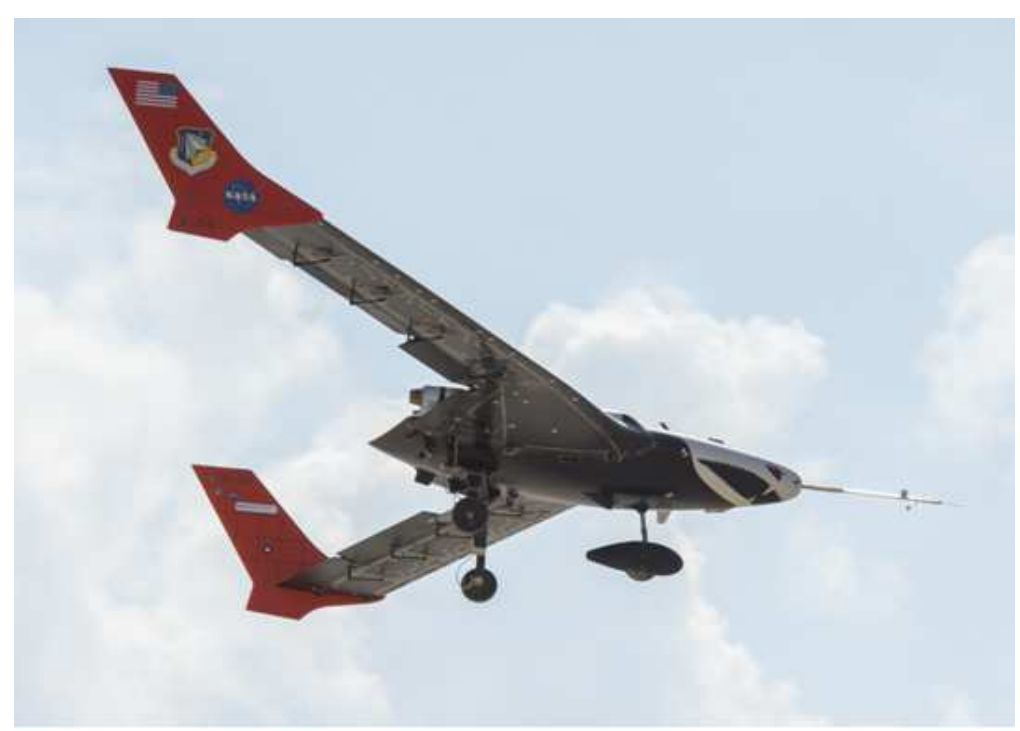

Fig. 7: Highly Flexible Wings Tested

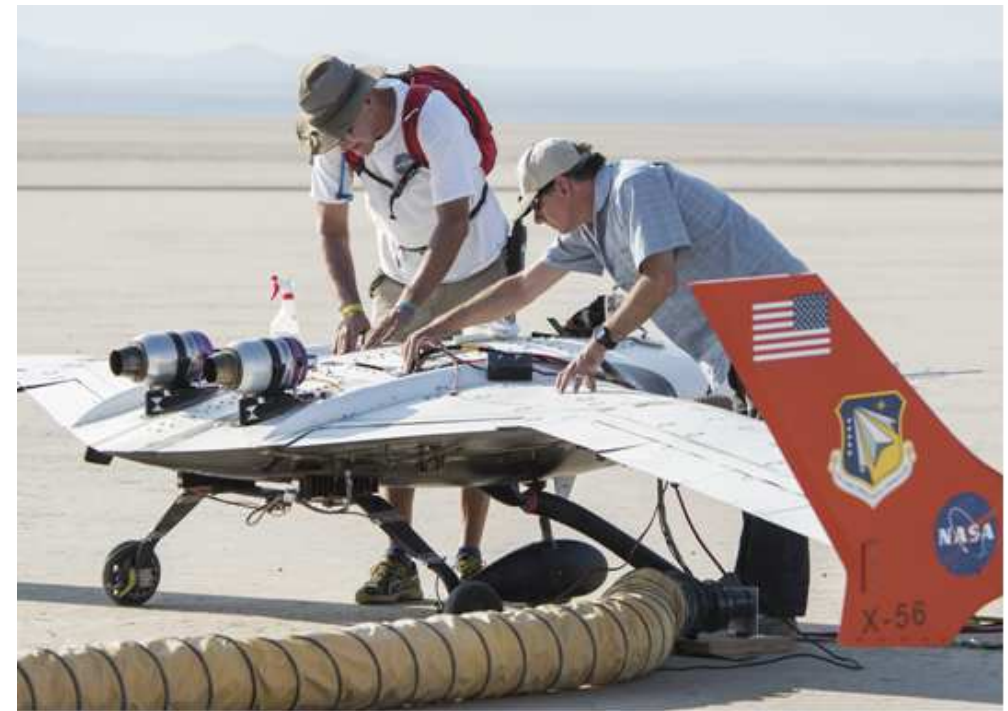

Fig. 8: Highly Flexible Wings Tested

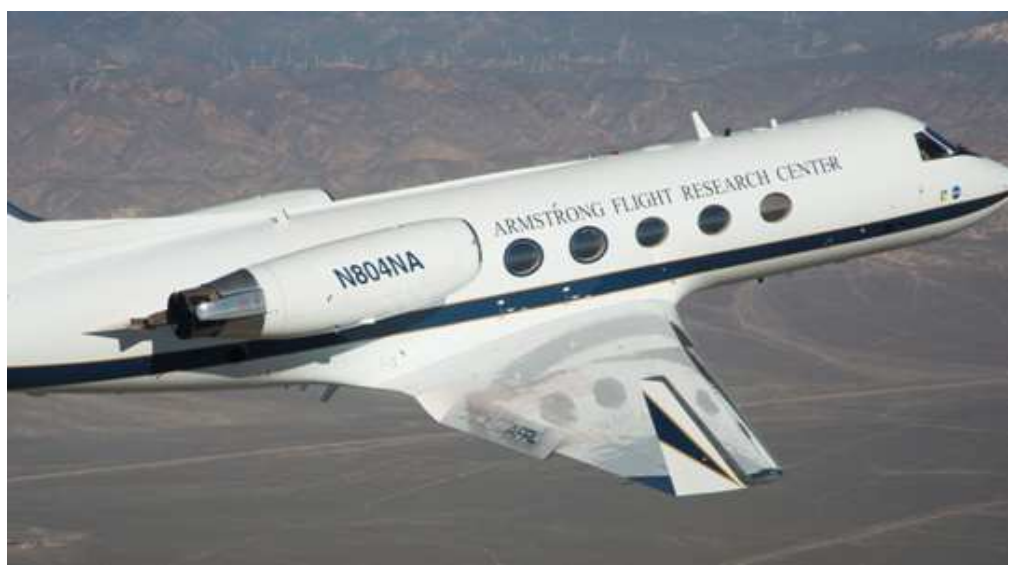

Fig. 9: The Adaptive Compliant Trailing Edge flight test project, or ACTE, is proving that a new flap design can reduce aircraft noise by as much as 30 percent on takeoff and landing 


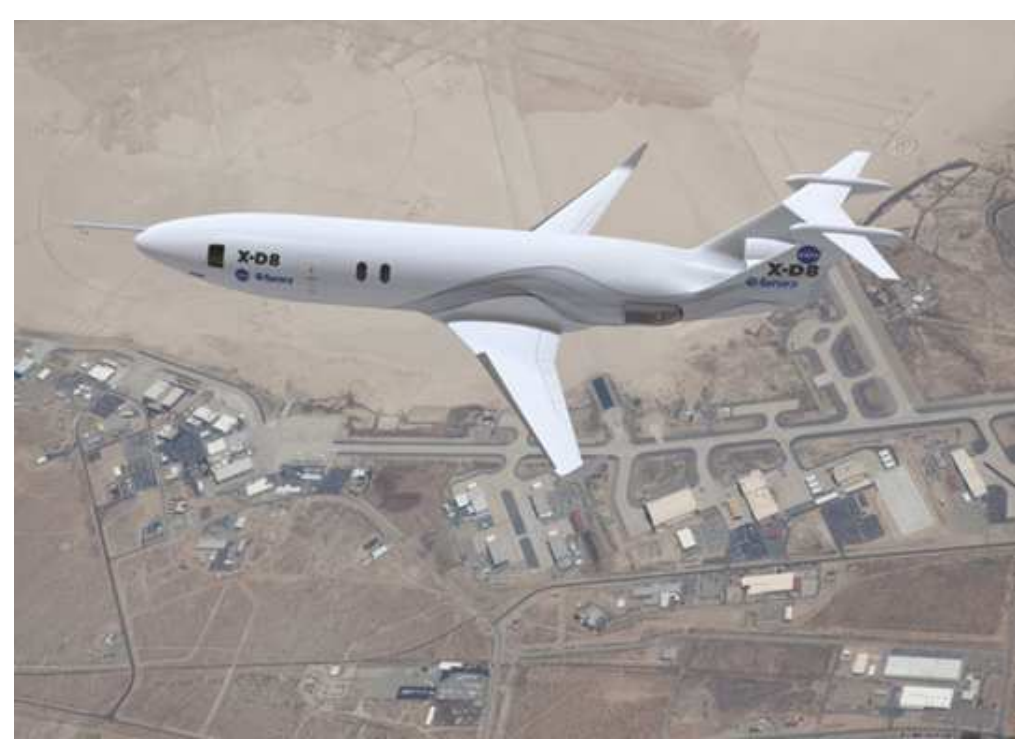

Fig. 10: Industry Provides NASA with Ideas for Next X-Plane

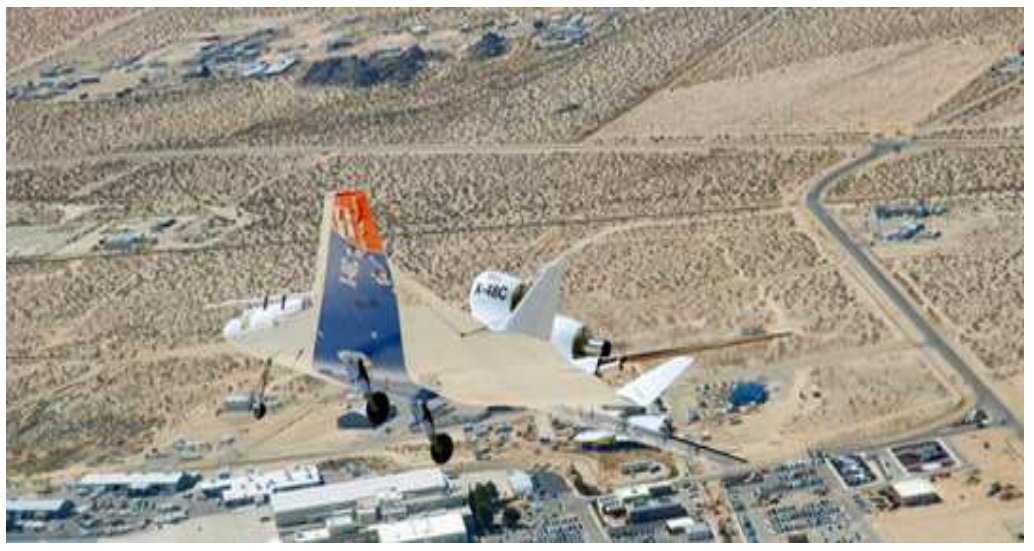

Fig. 11: The X-48C Hybrid Wing Body research aircraft banks right over NASA's Dryden Flight Research Center at Edwards Air Force Base during one of the sub-scale aircraft's final test flights on Feb. 28, 2013

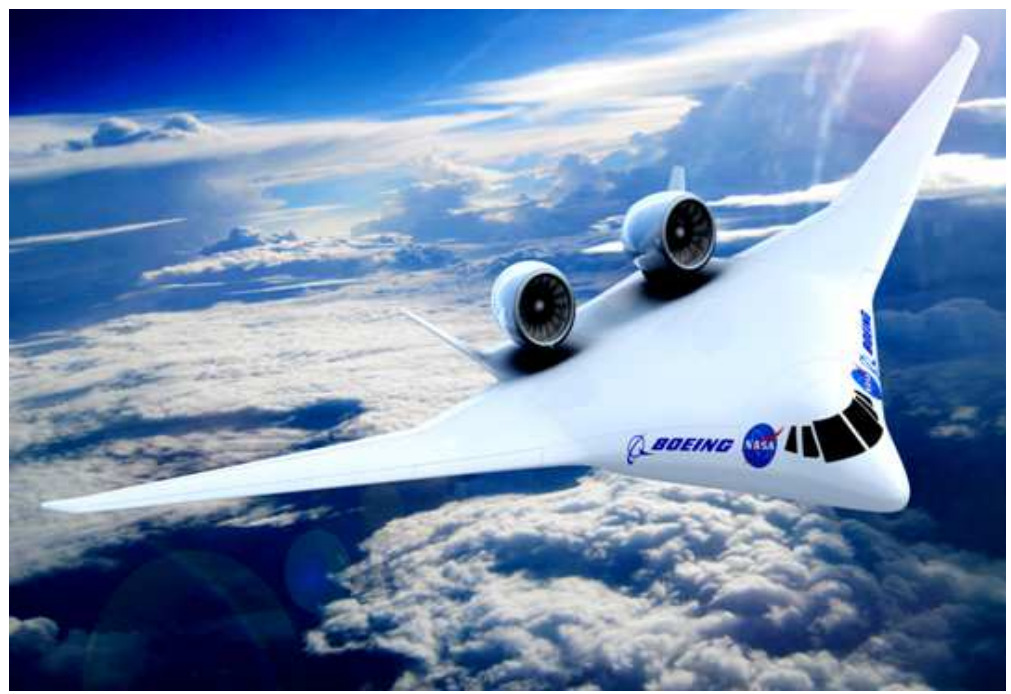

Fig. 12: The Boeing Company's blended wing body design concept 
A risk reduction flight Aug. 31 from Armstrong demonstrated that past challenges experienced during takeoffs and landings are resolved, said Cheng Moua, X$56 \mathrm{~A}$ project manager.

To mitigate the downsides of earlier flights, researchers redesigned the landing gear and braking system to improve performance, Moua explained.

The flight controller was revised, extensive analysis completed and ground vibration data collected to update theoretical models to improve predictions on how the aircraft will fly.

Long, lightweight flexible wings similar to the ones on the X-56 are crucial to the design of future long-range aircraft and are especially susceptible to a destructive vibration known as flutter at lower speeds. If those vibrations are not alleviated, they could cause controllability challenges or potentially compromise the aircraft's structure.

Flutter hasn't been restrained before on an aircraft like the X-56, Moua said. Flutter suppression could lead to improved ride quality, efficiency, safety and the longevity of flexible aircraft structures, he added.

"We want to show that this kind of wing can be built and the control technology exists to suppress flutter on them," Moua said.

The flights will build up slowly as each step is meticulously executed. New techniques will be tested to collect data and make sense of it and a methodology will be developed to confirm flutter was suppressed, he said. Armstrong engineers developed a flight control system and advanced sensors to gather the information required to achieve the project's goals.

Lockheed Martin developed the small, remotely piloted aircraft for the U.S. Air Force Research Laboratory and transferred the aircraft to Armstrong for flight research. The program is funded through NASA's Advanced Air Transport Technology project and NASA's Flight Demonstration Capabilities project (Fig. 7-8).

The Adaptive Compliant Trailing Edge flight test project, or ACTE, is proving that a new flap design can reduce aircraft noise by as much as $30 \%$ on takeoff and landing.

The second phase of the project, ACTE II, which is expected to continue this fall and conclude at the end of the year, will build on the research and data collected on the flap locked in different positions in flight during the first phase. The second phase, taking place at Armstrong, also will validate the technology at higher speeds and research how the flaps impact aerodynamic forces that could improve fuel efficiency.

The goal of the ACTE flight test project is to investigate the capabilities of shape-changing surfaces and determine if advanced flexible trailing-edge wing flaps can improve aircraft aerodynamic efficiency, enhance fuel economy and reduce airport noise generated during takeoffs and landings.
"ACTE has tremendous potential to increase airframe efficiencies," said Kevin Weinert, ACTE project manager. "We have tested the flap at six positions to show we can take advantage of lightweight, efficient structures."

In 2014, engineers replaced the traditional 19-foot aluminum flaps for the ACTE wings on NASA's Gulfstream-III Subsonic Research Aircraft, or SCRAT. The Air Force Research Laboratory funded the flexible flaps that change shape, bend and are made of composite materials designed by FlexSys Inc.

Traditional flaps, when lowered, create gaps between the forward edge, the sides of the flaps and the wing surface.

A flexed wing configuration allows a level of control over how and where the wing responds to wind gusts. This design may significantly reduce a major source of airframe noise - making takeoff and landing quieter.

The first flight series for the ACTE took place in 2014 and 2015 at Armstrong, where relevant data were collected on the different flap settings and their ability to withstand the flight environment.

These flaps have the potential to be retrofitted to existing airplane wings as well as incorporated into new airliners. The controls on the experimental surfaces were locked on a specific setting and were restricted to a speed of 0.75 Mach, which is approximately 570 miles per hour.

Initially, flights with ACTE flaps were in a flexed configuration and limited to a maximum speed of 250 knots and 20,000 feet. ACTE II showed the technology was safely demonstrated in flight at speeds similar to commercial airliners at Mach 0.85 .

NASA is currently conducting data analyses to gain a better understanding of how these new wing flaps may affect aircraft fuel efficiency. The ACTE II flights will also analyze fuel flow through the engine to achieve accurate drag estimates at varied speeds, altitudes and weights, according to Weinert.

The ACTE project began under the former Environmentally Responsible Aviation project and then, due to promising benefits, was transitioned to the Flight Demonstrations and Capabilities project under the Integrated Systems Research Program in NASA's Aeronautics Research Mission Directorate (Fig. 9; Beaty, 2017), (Webster et al., 2018; Aversa et al., 2017a; 2017b; 2017c; 2017d; 2017e; 2017f; 2016a; 2016b; 2016c; 2016d; 2016e; 2016f; 2016g; 2016h; 2016i; 2016j; 2016k; 20161; 2016m; 2016n; 2016o; Mirsayar et al., 2017; Petrescu and Petrescu, 2016a; 2016b; 2016c; 2013a; 2013b; 2013c; 2013d; 2012a; 2012b; 2012c; 2012d; 2011a; 2011b; Petrescu, 2016; 2012a; 2012b; 2009; Petrescu and Calautit, 2016a; 2016b; Petrescu et al., 2016a; 2016b; 2016c; Petrescu et al., 2017a; 2017b; $2017 \mathrm{c} ; 2017 \mathrm{~d} ; 2017 \mathrm{e} ; 2017 \mathrm{f} ; 2017 \mathrm{~g} ; 2017 \mathrm{~h} ; 2017 \mathrm{i}$; 2017j; 2017k; 2017l; 2018 a-n; Zubritsky, 2017). 


\section{Results}

It will not take long before NASA's aeronautical innovations make a difficult decision.

As they head to the plans to launch a new supersonic $\mathrm{X}$ aircraft, in the coming years, researchers in developing agencies are developing a plan to build another X plan with a completely different focus.

For this X plan, attention is paid to technological demonstrations that will allow the industry to accelerate the development of quieter commercial aircraft, burn less fuel and emit fewer emissions than the most efficient planes flying today (Fig. 10-12).

The big question is how will the subsonic plane $\mathrm{X}$ be shown?

As a step in the decision-making process, NASA has recently called the aerospace industry for ideas. Four companies have received contracts to come up with five paper-based $\mathrm{x}$-ray configurations that meet very specific operational criteria.

"We were very pleased with the results." NASA has received much information to help us think about how to do it, "said Fay Collier, an associate officer of NASA's flight strategy.

Six-month studies have been required to define "vision systems," the advanced and advanced concepts of aircraft fit for operation in the nation's air transport system.

The concepts should include technologies that meet the 2035 targets such as reducing fuel consumption by $60-80 \%$, reducing emissions in all phases by over $80 \%$ and reducing perceived noise by more than $50 \%$ compared to quieter aircraft in 2005.

Many of the concepts reflect a further maturation of the research that industry and NASA have collaborated over the last decade, notably through the project responsible for environmental protection.

Six-month studies also covered Plan X; NASA's requirements were for a pilot vehicle that could safely fly in two or three hours at transonic speed and had a life of 500-1000 hours in the sky.

For planning purposes, each contractor would have assumed that the flight test program will be based on the California California Weapons Research Center, although other testing sites could be proposed and that the test program will be completed in 12 months in the first flight.

Above all, ideas have to be realistic, so it is possible for a company to build a business case for investment in aircraft production based on technology and systems demonstrated by plan X.

Moving forward, the industry should decide whether to invest or not.

Aurora Flight Sciences with D8 Bubble Double.

The D8 has two quarry sections that have been combined along the long road and a vertical stabilizer with a two-ribbed T-tail. Twin engines are mounted at the rear of the aircraft above the fuselage between the two vertical stabilizers.

With the more conventional tube and wing configuration, as well as the sports bolts.

Attractive attributes include the use of lightweight composite structures, advanced manufacturing methods, ease of operation and cost savings in operating the aircraft during its lifetime.

And with the engines attached as they are, the air flowing through the top of the aircraft is moved by the engines to reduce the total decrease - a concept known as the edge layer intake (Fig. 10).

Boeing with Mixed Body (BWB). Aspect, this idea resembles a larger version of the $\mathrm{X}-48$ subscale that has already flown successfully.

A BWB aircraft has a perfect combination of a wing in the main body, dual motors mounted on the top of the aircraft platform and the engines that surround the smaller wings of the vertical tail.

Among other things, the idea here is to validate the aerodynamic performance and stability of a large-scale BWB through all phases of flight - take-off, cruise and landing - and the benefits of reducing the noise of having motors mounted on top of the lower fuselage 11).

Boeing with a cross-legged (TTBW). More traditional in the appearance of the tube and its wing, the difference comes from the fact that the wing is much longer and narrower - a high aspect ratio compared to conventional air.

The structure of the longer wing is supported by an armrest, practically similar to that seen in most singleengine Cessna general aviation aircraft.

The intention is to demonstrate the aerodynamic and structural advantages of the TTWW and to validate that while flying at cruising altitude, it can achieve its fuel reduction targets.

Another objective is to demonstrate a methodology and requirements to certify a non-traditional aeronautical structure (Fig. 12).

Lockheed Martin with a Hybrid Wing Body (HWB). As its names imply, Lockheed Martin's concept combines features of blending the wing into the aircraft body, yet still retaining the suggestion of a T-tailed tubeand-wing configuration.

Another unique feature is that its twin engines are mounted on pylons attached to and trailing the wing, with the engine inlets rising above the top of the wing.

As with the other X-plane proposals, Lockheed Martin would use this design to demonstrate its aerodynamic and propulsion efficiencies; reductions in fuel burn, emissions and noise; and its ability to quickly mature technology to take advantage of future opportunities (Fig. 13). 


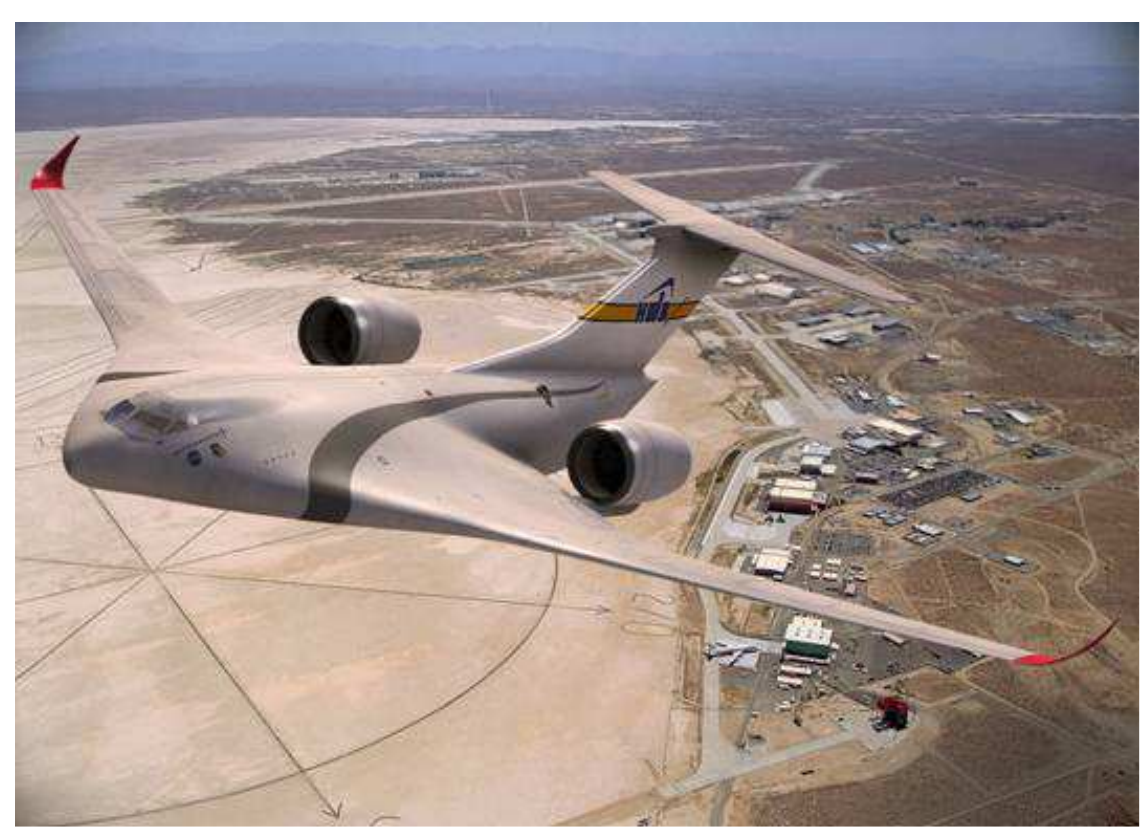

Fig. 13: Lockheed Martin's hybrid wing body design concept

\section{Discussion}

It is common to see clouds in the form of the sky, known as contrails, which are behind the engines of a reaction plan (Fig. 1). What is not always visible is a wind whirl that comes out of the top of each wing - like two small horizontal tornadoes - leaving behind a turbulent awakening behind the vehicle. Awakening is a destabilizing flight hazard, especially for smaller aircraft that have the same flight path.

Recent research at the University of Illinois has shown that although most of the wings used today create these turbulent vortices, wing geometry can be designed to reduce or eliminate almost the entire comma. In the study, the characteristics of vortex and awakening were calculated for three classical wings: wings and elliptical wings developed in the classical R.T. Jones and Ludwig Prandt.

"The configuration of the elliptical wings has been used as the gold standard of aerodynamic efficiency for the best part of a century.

We teach our students that they have optimal load characteristics and that they are often used when looking at wings efficiency, for example by minimizing traction, said Phillip Ansell, assistant professor at the Department of Aerospace Engineering at U of I.

In a previous experimental study on optimizing wing configurations, Ansell has learned that you can achieve the efficiency of the wing system with a non-elliptical wing profile.

Previous academic studies have shown that, in theory, there are other models that actually offer less resistance to a flat wing for a fixed amount of elevator generation. But what is missing is a real apple experiment - something else to prove it.

In this new research, Ansell and his graduate student, Prateek Ranjan, used the real data from the previous study to analyze the configurations of the three wings.

"We followed this because we saw a certain curiosity in our measurements in the previous experiment."

"In this new study, we simulated the flow of these three wings and we saw significant differences in how the vortexing and awakening of three Wings Wings Jones and Prandtl did not have peaks like elliptical wings, they had a more gradual deformation of the entire ditch than the immediate consistency of change."

Now we know we can delay the formation of structures, the vortex awakens and increases our wishes for distance to pass 12 times, making it weaker and less dangerous for the plane to pass through it. "

Ansell said that this information could be used to regulate flight mode between aircraft or to develop a new ideal configuration for loading the take-off and landing lift and to further reduce the distance between the aircraft in the same way as the bodies.

"The tip of the wing tends to escape when it forms in the atmosphere. So the time needed to dissipate the vortex must be removed, the next air that goes in the same direction it can create for the aircraft behind them, because it can be unpredictable to cause wings to Jones or Prandtl, would lead to much less turbulent air behind a plane, Ansell said.

You'd think Ansell's conclusion is to use only the Jones or Prandtl wings, but it's not. 
"One of the things that first attracted me to aerodynamics is that the correct answer always depends on your constraints.

If you are building a tiny unmanned vehicle that will fly at a low speed, you will get a different solution for design needs than if you build an aircraft that will drive people at high altitudes and high speeds So from a technical point of view, you could claim that the three types of wings are the best solution. The question is: what are your driving constraints such as wings and weight, behind the choice of a?

Ansell added that this is a basic study and does not intend to advise a particular airplane designer or company.

"We look at how wing wings and information can be used to understand how the wind swirl process takes place. This study allows us to be aware of how the wings configuration affects wind formation and wakes up studying the extremes of the wind immediate and delayed," Ansell said.

"Interestingly, I found that one of the worst offenders creating vortexes is really the distribution" (Ranjan and Ansell, 2018).

\section{Conclusion}

It is common to see clouds in the form of the sky, known as contrails, which are behind the engines of a reaction plan. What is not always visible is a wind whirl that comes out of the top of each wing - like two small horizontal tornadoes - leaving behind a turbulent awakening behind the vehicle. Awakening is a destabilizing flight hazard, especially for smaller aircraft that have the same flight path.

Recent research at the University of Illinois has shown that although most of the wings used today create these turbulent vortices, wing geometry can be designed to reduce or eliminate almost the entire comma. In the study, the characteristics of vortex and awakening were calculated for three classical wings: wings and elliptical wings developed in the classical R.T. Jones and Ludwig Prandt.

\section{Acknowledgement}

We acknowledge and thank $\mathrm{Mr}$ Taher M. AbuLebdeh, Associate Prof at North Carolina A and T State Univesity, United States and Mr Muftah H. El-Naas PhD MCIC FICCE QAFCO Chair Professor in Chemical Process Engineering Gas Processing Center College of Engineering Qatar University and Ms Shweta Agarwala, Senior Research Scientist at Singapore Center for 3D Printing Nanyang Technological University Singapore for their suggestions and comments.

\section{Funding Information}

Research contract: Contract number 36-5-4D/1986 from 24IV1985, beneficiary CNST RO (Romanian National Center for Science and Technology) Improving dynamic mechanisms internal combustion engines. All these matters are copyrighted. Copyrights: 548cgiywDssin, from: 22-04-2010, 08:48:48.

\section{Author's Contributions}

All the authors contributed equally to prepare, develop and carry out this manuscript.

\section{Ethics}

This article is original and contains unpublished material. The corresponding author confirms that all of the other authors have read and approved the manuscript and no ethical issues involved.

\section{References}

Aversa, R., F.I.T. Petrescu, R.V. Petrescu and A. Apicella, 2016a. Biomimetic FEA bone modeling for customized hybrid biological prostheses development. Am. J. Applied Sci., 13: 1060-1067. DOI: 10.3844/ajassp.2016.1060.1067

Aversa, R., D. Parcesepe, R.V. Petrescu, G. Chen and F.I.T. Petrescu et al., 2016b. Glassy amorphous metal injection molded induced morphological defects. Am. J. Applied Sci., 13: 1476-1482.

DOI: 10.3844/ajassp.2016.1476.1482

Aversa, R., R.V. Petrescu, F.I.T. Petrescu and A. Apicella, 2016c. Smart-factory: Optimization and process control of composite centrifuged pipes. Am. J. Applied Sci., 13: 1330-1341. DOI: 10.3844/ajassp.2016.1330.1341

Aversa, R., F. Tamburrino, R.V. Petrescu, F.I.T. Petrescu and M. Artur et al., $2016 \mathrm{~d}$. Biomechanically inspired shape memory effect machines driven by muscle like acting NiTi alloys. Am. J. Applied Sci., 13: 1264-1271. DOI: 10.3844/ajassp.2016.1264.1271

Aversa, R., E.M. Buzea, R.V. Petrescu, A. Apicella and M. Neacsa et al., 2016e. Present a mechatronic system having able to determine the concentration of carotenoids. Am. J. Eng. Applied Sci., 9: 1106-1111. DOI: 10.3844/ajeassp.2016.1106.1111

Aversa, R., R.V. Petrescu, R. Sorrentino, F.I.T. Petrescu and A. Apicella, 2016f. Hybrid ceramo-polymeric nanocomposite for biomimetic scaffolds design and preparation. Am. J. Eng. Applied Sci., 9: 1096-1105. DOI: 10.3844/ajeassp.2016.1096.1105

Aversa, R., V. Perrotta, R.V. Petrescu, C. Misiano and F.I.T. Petrescu et al., 2016g. From structural colors to super-hydrophobicity and achromatic transparent protective coatings: Ion plating plasma assisted $\mathrm{TiO}_{2}$ and $\mathrm{SiO}_{2}$ Nano-film deposition. Am. J. Eng. Applied Sci., 9: 1037-1045.

DOI: 10.3844 /ajeassp.2016.1037.1045 
Aversa, R., R.V. Petrescu, F.I.T. Petrescu and A. Apicella, 2016h. Biomimetic and evolutionary design driven innovation in sustainable products development. Am. J. Eng. Applied Sci., 9: 1027-1036. DOI: 10.3844/ajeassp.2016.1027.1036

Aversa, R., R.V. Petrescu, A. Apicella and F.I.T. Petrescu, 2016i. Mitochondria are naturally micro robots-a review. Am. J. Eng. Applied Sci., 9: 991-1002. DOI: 10.3844/ajeassp.2016.991.1002

Aversa, R., R.V. Petrescu, A. Apicella and F.I.T. Petrescu, 2016j. We are addicted to vitamins $\mathrm{C}$ and E-A review. Am. J. Eng. Applied Sci., 9: 1003-1018. DOI: 10.3844/ajeassp.2016.1003.1018

Aversa, R., R.V. Petrescu, A. Apicella and F.I.T. Petrescu, 2016k. Physiologic human fluids and swelling behavior of hydrophilic biocompatible hybrid ceramo-polymeric materials. Am. J. Eng. Applied Sci., 9: 962-972.

DOI: 10.3844 /ajeassp.2016.962.972

Aversa, R., R.V. Petrescu, A. Apicella and F.I.T. Petrescu, 20161. One can slow down the aging through antioxidants. Am. J. Eng. Applied Sci., 9: 1112-1126. DOI: 10.3844/ajeassp.2016.1112.1126

Aversa, R., R.V. Petrescu, A. Apicella and F.I.T. Petrescu, 2016m. About homeopathy or $\ll$ Similia similibus curentur $\gg$. Am. J. Eng. Applied Sci., 9: 1164-1172. DOI: 10.3844/ajeassp.2016.1164.1172

Aversa, R., R.V. Petrescu, A. Apicella and F.I.T. Petrescu, 2016n. The basic elements of life's. Am. J. Eng. Applied Sci., 9: 1189-1197. DOI: 10.3844/ajeassp.2016.1189.1197

Aversa, R., F.I.T. Petrescu, R.V. Petrescu and A. Apicella, 2016o. Flexible stem trabecular prostheses. Am. J. Eng. Applied Sci., 9: 1213-1221. DOI: 10.3844/ajeassp.2016.1213.1221

Aversa, R., R.V.V. Petrescu, A. Apicella and F.I.T. Petrescu, 2017a. Nano-diamond hybrid materials for structural biomedical application. Am. J. Biochem. Biotechnol., 13: 34-41. DOI: 10.3844/ajbbsp.2017.34.41

Aversa, R., R.V. Petrescu, B. Akash, R.B. Bucinell and J.M. Corchado et al., 2017b. Kinematics and forces to a new model forging manipulator. Am. J. Applied Sci., 14: 60-80. DOI: 10.3844/ajassp.2017.60.80

Aversa, R., R.V. Petrescu, A. Apicella, I.T.F. Petrescu and J.K. Calautit et al., 2017c. Something about the $\mathrm{V}$ engines design. Am. J. Applied Sci., 14: 34-52. DOI: 10.3844/ajassp.2017.34.52

Aversa, R., D. Parcesepe, R.V.V. Petrescu, F. Berto and G. Chen et al., 2017d. Process ability of bulk metallic glasses. Am. J. Applied Sci., 14: 294-301. DOI: 10.3844/ajassp.2017.294.301

Aversa, R., R.V.V. Petrescu, B. Akash, R.B. Bucinell and J.M. Corchado et al., 2017e. Something about the balancing of thermal motors. Am. J. Eng. Applied Sci., 10: 200-217.

DOI: 10.3844/ajeassp.2017.200.217
Aversa, R., R.V. Petrescu, A. Apicella and F.I.T. Petrescu, 2017f. Modern transportation and photovoltaic energy for urban ecotourism. Transylvanian Rev. Admin. Sci., 13: 5-20. DOI: $10.24193 /$ tras.SI2017.1

Beaty, J., 2017. Hear This: 30 Percent Less Noise. NASA Armstrong Flight Research Center. Oct. 11, 2017. Editor: Yvonne Gibbs.

Harrington, J.D. and Leslie Williams, 2015. NASA Successfully Tests Shape-Changing Wing for Next Generation Aviation, April 28, 2015. RELEASE 15-072.

Mirsayar, M.M., V.A. Joneidi, R.V.V. Petrescu, F.I.T. Petrescu and F. Berto, 2017. Extended MTSN criterion for fracture analysis of soda lime glass. Eng. Fracture Mechan., 178: 50-59.

DOI: 10.1016/j.engfracmech.2017.04.018

Petrescu, F.I.T., 2009. New aircraft. Proceedings of the 3rd International Conference on Computational Mechanics, Oct. 29-30, Brasov, Romania.

Petrescu, F.I.T., 2012a. Cold Nuclear Fusion. 1st Edn., Create Space, USA, ISBN-10: 1478234261, pp: 80.

Petrescu, F.I.T., 2012b. Particle annihilation - a source of renewable energy? Infinite Energy Magazine, LuLu Publishers, USA.

Petrescu, F.I.T., 2016 Valorificarea Traditiei Ingineresti Romanesti-I. 1st Edn., CreateSpace Independent Publishing Platform, ISBN-10: 1536889946, pp: 152.

Petrescu, F.I.T. and J.K. Calautit, 2016a. About nano fusion and dynamic fusion. Am. J. Applied Sci., 13: 261-266. DOI: 10.3844/ajassp.2016.261.266

Petrescu, F.I. and J.K. Calautit, 2016b. About the light dimensions. Am. J. Applied Sci., 13: 321-325. DOI: 10.3844 /ajassp.2016.321.325

Petrescu, F.I. and R.V. Petrescu, 2011a. Memories about Flight. 1st Edn., CreateSpace, pp: 652.

Petrescu, F.I. and R.V. Petrescu, 2011b. Mechanical Systems, Serial and Parallel. 1st Edn., lulu.com Publisher, London, UK. ISBN-10: 1446600394, pp: 124.

Petrescu, R.V. and F.I.T. Petrescu, 2012a. Northrop. 1st Edn., Books on Demand, ISBN-10: 3848209322 , pp: 142.

Petrescu, F.I. and R.V. Petrescu, 2012b. New Aircraft II. 1st Edn., Books on Demand, pp: 138.

Petrescu, F.I. and R.V. Petrescu, 2012c. MecatronicaSisteme Seriale Si Paralele. 1st Edn., Create Space Publisher, USA. ISBN-13: 978-1-4750-6613-5, pp: 128.

Petrescu, F.I. and R.V. Petrescu, 2012d. Kinematics of the planar quadrilateral mechanism. ENGEVISTA, 14: 345-348. 
Petrescu, R.V. and F.I. Petrescu, 2013a. Lockheed Martin. 1st Edn., CreateSpace, pp: 114.

Petrescu, R.V. and F.I. Petrescu, 2013b. Northrop. 1st Edn., CreateSpace, pp: 96.

Petrescu, R.V. and F.I. Petrescu, 2013c. The Aviation History or New Aircraft I Color. 1st Edn., CreateSpace, pp: 292.

Petrescu, F.I. and R.V. Petrescu, 2013d. Cinematics of the 3R dyad. ENGEVISTA, 15: 118-124.

Petrescu, F.I. and R.V. Petrescu, 2016a. Parallel moving mechanical systems kinematics. ENGEVISTA, 18:455-491.

Petrescu, F.I. and R.V. Petrescu, 2016b. Direct and inverse kinematics to the anthropomorphic robots. ENGEVISTA, 18: 109-124.

Petrescu, F.I. and R.V. Petrescu, 2016c. Dynamic cinematic to a structure 2R. Revista Geintec-Gestao Inovacao E Tecnol., 6: 3143-3154.

Petrescu, R.V.V., R. Aversa, A. Apicella, F. Berto and S. Li et al., 2016a. Ecosphere protection through green energy. Am. J. Applied Sci., 13: 1027-1032.

DOI: 10.3844/ajassp.2016.1027.1032

Petrescu, F.I.T., A. Apicella, R.V.V. Petrescu, S.P. Kozaitis and R.B. Bucinell et al., $2016 \mathrm{~b}$. Environmental protection through nuclear energy. Am. J. Applied Sci., 13:941-946. DOI: 10.3844/ajassp.2016.941.946

Petrescu, R.V., R. Aversa, A. Apicella and F.I. Petrescu, 2016c. Future medicine services robotics. Am. J. Eng. Applied Sci., 9: 1062-1087. DOI: 10.3844/ajeassp.2016.1062.1087

Petrescu, R.V., R. Aversa, B. Akash, F. Berto and A. Apicella et al., 2017a. Forces of a 3R Robot. J. Mechatron. Robot., 1: 1-14. DOI: $10.3844 /$ jmrsp.2017.1.14

Petrescu, R.V., R. Aversa, B. Akash, F. Berto and A. Apicella et al., 2017b. Direct geometry and cinematic to the MP-3R systems. J. Mechatron. Robot., 1: 15-23. DOI: 10.3844/jmrsp.2017.15.23

Petrescu, R.V., R. Aversa, B. Akash, F. Berto and A. Apicella et al., 2017c. Dynamic elements at MP3R. J. Mechatron. Robot., 1: 24-37. DOI: $10.3844 /$ jmrsp.2017.24.37

Petrescu, R.V., R. Aversa, B. Akash, F. Berto, A. Apicella and F.I.T. Petrescu, 2017d. Geometry and direct kinematics to MP3R with $4 \times 4$ operators. J. Mechatron. Robot., 1: 38-46. DOI: 10.3844 /jmrsp.2017.38.46

Petrescu, R.V., R. Aversa, A. Apicella, M.M. Mirsayar and S. Kozaitis et al., 2017e. Current stage in the field of mechanisms with gears and rods. J. Mechatron. Robot., 1: 47-57.

DOI: $10.3844 / j m r s p .2017 .47 .57$
Petrescu, R.V., R. Aversa, A. Apicella, M.M. Mirsayar and S. Kozaitis et al., 2017f. Geometry and inverse kinematic at the MP3R mobile systems. J. Mechatron. Robot., 1: 58-65. DOI: 10.3844 jmrsp.2017.58.65

Petrescu, R.V., R. Aversa, A. Apicella, M.M. Mirsayar and S. Kozaitis et al., 2017g. Synthesis of optimal trajectories with functions control at the level of the kinematic drive couplings. J. Mechatron. Robot., 1: 66-74. DOI: 10.3844 jmrsp.2017.66.74

Petrescu, R.V., R. Aversa, A. Apicella, M.M. Mirsayar and S. Kozaitis et al., 2017h. The inverse kinematics of the plane system 2-3 in a mechatronic MP2R system by a trigonometric method. J. Mechatron. Robot., 1: 75-87. DOI: 10.3844/jmrsp.2017.75.87

Petrescu, R.V., R. Aversa, A. Apicella, M.M. Mirsayar and S. Kozaitis et al., 2017i. Serial, anthropomorphic, spatial, mechatronic systems can be studied more simply in a plan. J. Mechatron. Robot., 1: 88-97. DOI: 10.3844/jmrsp.2017.88.97

Petrescu, R.V., R. Aversa, A. Apicella, M.M. Mirsayar and S. Kozaitis et al., 2017j. Analysis and synthesis of mechanisms with bars and gears used in robots and manipulators. J. Mechatron. Robot., 1: 98-108. DOI: $10.3844 /$ jmrsp.2017.98.108

Petrescu, R.V., R. Aversa, A. Apicella, M.M. Mirsayar and S. Kozaitis et al., 2017k. Speeds and accelerations in direct kinematics to the MP3R systems. J. Mechatron. Robot., 1: 109-117. DOI: $10.3844 /$ jmrsp.2017.109.117

Petrescu, R.V., R. Aversa, A. Apicella, M.M. Mirsayar and S. Kozaitis et al., 20171. Geometry and determining the positions of a plan transporter manipulator. J. Mechatron. Robot., 1: 118-126. DOI: $10.3844 /$ jmrsp.2017.118.126

Petrescu, RV., R. Aversa, A. Apicella, M.M. Mirsayar and S. Kozaitis et al., 2018a. NASA Started a Propeller set on Board Voyager 1 after 37 Years of Break. Am. J. Eng. Applied Sci., 11: 66-77.

DOI: 10.3844/ajeassp.2018.66.77 Petrescu, RV., R. Aversa, A. Apicella, M.M. Mirsayar and S. Kozaitis et al., 2018b. There is Life on Mars? Am. J. Eng. Applied Sci., 11: 78-91.

DOI: 10.3844/ajeassp.2018.78.91

Petrescu, RV., R. Aversa, A. Apicella and FIT. Petrescu, 2018c. Friendly Environmental Transport. Am. J. Eng. Applied Sci., 11: 154-165.

DOI: 10.3844 /ajeassp.2018.154.165

Petrescu, RV., R. Aversa, A. Apicella, 2018d. Buses Running on Gas. Am. J. Eng. Applied Sci., 11: 186-201. DOI: 10.3844/ajeassp.2018.186.201

Petrescu, RV., R. Aversa et al., 2018e. Some Aspects of the Structure of Planar Mechanisms. Am. J. Eng. Applied Sci., 11: 245-259.

DOI: 10.3844/ajeassp.2018.245.259 
Petrescu, RV., R. Aversa et al., 2018f. The Forces of a Simple Carrier Manipulator. Am. J. Eng. Applied Sci., 11: 260-272.

DOI: 10.3844/ajeassp.2018.260.272

Petrescu, RV., R. Aversa et al., 2018g. The Dynamics of the Otto Engine. Am. J. Eng. Applied Sci., 11: 273-287. DOI: 10.3844/ajeassp.2018.273.287

Petrescu, RV., R. Aversa et al., 2018h. NASA Satellites Help us to Quickly Detect Forest Fires. Am. J. Eng. Applied Sci., 11: 288-296.

DOI: 10.3844/ajeassp.2018.288.296

Petrescu, RV., R. Aversa, et al., 2018i. Kinematics of a Mechanism with a Triad. Am. J. Eng. Applied Sci., 11: 297-308. DOI: 10.3844/ajeassp.2018.297.308

Petrescu, RV., R. Aversa et al., 2018j. Total Static Balancing and Kinetostatics of the 3R Base Cinematic Chain. J. Mechatron. Robot., 2: 1-13. DOI: $10.3844 /$ jmrsp.2018.1.13

Petrescu, RV., R. Aversa et al., 2018k. Switching from Flat to Spatial Motion to 3R Mechatronic Systems. J. Mechatron. Robot., 2: 14-22.

DOI: $10.3844 / \mathrm{jmrsp} .2018 .14 .22$

Petrescu, RV., R. Aversa et al., 20181. The Dynamics of the Planar Cinematic Balanced Chain at the Plan Module 3R. J. Mechatron. Robot., 2: 23-34. DOI: 10.3844/jmrsp.2018.23.34

Petrescu, RV., R. Aversa et al., 2018m. Dynamic kinematics of the plan balanced chain at the planar module 3R. J. Mechatron. Robot., 2: 35-44. DOI: 10.3844 /jmrsp.2018.35.44

Petrescu, RV., R. Aversa et al., 2018n. Inverse Kinematics of a Stewart Platform. J. Mechatron. Robot., 2: 45-59. DOI: 10.3844/jmrsp.2018.45.59

Ranjan, P. and P.J. Ansell, 2018. Computational analysis of vortex wakes without near-field rollup characteristics. It appears in the Journal of Aircraft. https://aerospace.illinois.edu/news/researchexamines-wing-shapes-reduce-vortex-and-wake

Webster, G., J. LaVista, L. Cantillo and D. Brown, 2018. Steep slopes on mars reveal structure of buried ice. Jet Propulsion Laboratory, Pasadena, California Institute of Technology.

Zubritsky, E., 2017. Exoplanet has smothering stratosphere without water. NASA's Jet Propulsion Laboratory, Pasadena, California Institute of Technology.

\section{Source of Figures}

Fig. 1:

https://www.sciencedaily.com/images/2018/05/1805141

Fig. 2:

$$
\text { 85916_1_540x360.jpg }
$$

http://storage0.dms.mpinteractiv.ro/media/2/84/2031/141 76594/1/nasa-acte.jpg

Fig. 3-5:

https://www.nasa.gov/feature/aviation-renaissance-nasaadvances-concepts-for-next-gen-aircraft

Fig. 6:

https://www.nasa.gov/sites/default/files/thumbnails/imag e/lbfd-vehicle2.jpg

Fig. 7:

https://www.nasa.gov/sites/default/files/thumbnails/imag e/afrc2017-0246-45.jpg

Fig. 8:

https:/www.nasa.gov/sites/default/files/thumbnails/imag e/afrc2017-0246-06.jpg

Fig. 9:

https://www.nasa.gov/sites/default/files/thumbnails/imag e/ed15-0076-03.jpg

Fig. 10:

https://www.nasa.gov/aero/industry-provides-nasa-withideas-for-next-x-plane

Fig. 11:

https://www.nasa.gov/topics/aeronautics/features/X48 research ends.html

Fig. 12:

https://www.nasa.gov/sites/default/files/thumbnails/imag e/2-bwb_xplane_composed_boeingnasa.jpg

Fig. 13:

https://www.nasa.gov/sites/default/files/thumbnails/imag e/4-lm_-_hwb_demo_own_compass.png 